\title{
A study of proteases throughout the life cycle of Trichinella spiralis
}

\author{
Rosa Ma Ros-Moreno, Celia Vázquez-López, Consuelo Giménez-Pardo, Cristina de Armas-Serra and \\ Filomena Rodríguez-Caabeiro
}

Laboratory of Parasitology, Faculty of Pharmacy, University of Alcalá, Alcalá de Henares 28871, Madrid, Spain

Key words: Trichinella spiralis, proteases, life cycle

\begin{abstract}
In the present report we study the proteolytic activity of the excretion-secretion and crude extracts of different stages of Trichinella spiralis (Owen, 1835) Railliet, 1895, (muscle-stage larvae, adult worms before and after mating, and newborn larvae) using natural substrates (structural and hematic mammalian proteins). The analysis of the results allow us to set up a certain stage-specificity, as well as an important relationship between the protease patterns throughout the parasite life cycle and how the parasite may overcome both mechanical and humoral barriers within the host. Muscle-stage larvae present a great activity against structural proteins (collagen), while newborn larvae and adult worms degrade principally hematic proteins (hemoglobin, fibrinogen and immunoglobulin G).
\end{abstract}

It is known that parasite proteases present in the crude extract as well as in the excretion-secretion products (ESP) are enzymes implicated in important biological aspects of parasites (Polzer and Conradt 1994, Todorova et al. 1995, Vázquez-López et al. 1999). Sometimes, moreover, it has been demonstrated that these molecules are stage-specific (McKerrow and Dohenhoff 1988, Britton et al. 1992) and that these changes in the proteases pattern could be related with the breakdown of both mechanical and humoral barriers that the parasite finds within the hosts (Moczon and Wranicz 1999).

Trichinella spiralis (Owen, 1835) Railliet, 1895, is a nematode parasite with an autoheteroxenous life cycle. All its developmental stages are found in the same host but showing different localisation, intestinal and parenteral (Despommier 1983, Soulé 1991). Up to date, no relationship between proteolytic activity and development of this parasite has been established. The presence of proteases has been reported in crude extract and ESP of the muscle-stage larvae (Criado-Fornelio et al. 1992, Armas-Serra et al. 1995, Moczon and Wranicz 1999), ESP of 6-day-old adults (Todorova et al. 1995) and histochemically in 48 to $72 \mathrm{~h}$ old newborn larvae (Moczon and Wranicz 1999), but all these results have been obtained with different experimental conditions as well as with different Trichinella isolates. The aims of this study were twofold: i) to analyse, by means of spectrophotometric and electrophoretic methods using different substrates, structural proteins (collagen and myosin) and hematic proteins (fibrinogen, hemoglobin and immunoglobulin G), the proteolytic pattern of muscle-stage larvae (crude extract and ESP), adult worms before and after mating (crude extract and ESP of adults 3 and 6 days old) and newborn larvae (crude extract); and ii) to relate these activities with the parasite life cycle.

\section{MATERIALS AND METHODS}

Parasite collection

Muscle-stage larvae. Muscle-stage larvae of Trichinella spiralis (GM-1) were recovered from experimentally infected NMRI mice by standard pepsin digestion at 35-45 days postinfestation (p.i.) (Brand et al. 1952).

Adult worms. Adult worms were collected by the Baermann technique during $2 \mathrm{~h}$ at $37^{\circ} \mathrm{C}$ from the intestines of NMRI mice experimentally infected 3 or 6 days previously.

Newborn larvae. Twenty-four hours old newborn larvae were collected after the maintenance in vitro of adult worms obtained from the intestine of NMRI mice experimentally infected $5,6,7$ or 8 days previously. The maintenance conditions were: approximately 5000 adults, males and females, in $15 \mathrm{ml}$ of Hank's solution (Sigma) supplemented with $1 \% 199$ medium (Sigma), penicillin $\left(2 \mathrm{mg} \mathrm{ml}^{-1}\right)$ and streptomycin sulphate $\left(1 \mathrm{mg} \mathrm{ml}^{-1}\right)$ at $37^{\circ} \mathrm{C}$ during $24 \mathrm{~h}$. Following separation from the adults by filtration, newborn larvae were washed by sedimentation in $10 \mathrm{mM}$ phosphate buffer (PBS, pH 7.2).

\section{Preparation of parasite material}

Crude extract. Muscle-stage larvae or adult worms (3 or 6 days old) were homogenised in a glass-Teflon homogeniser in $10 \mathrm{mM}$ PBS (pH 7.2) and centrifuged at $4^{\circ} \mathrm{C}$ and at $100,000 \mathrm{~g}$ for $30 \mathrm{~min}$. The supernatants were recovered and centrifuged again, this last supernatant being considered as the crude extract. Newborn larvae crude extract was obtained by sonication with 5 -second pulses at output 4 on an ultrasonic cell disruptor (Microson) with 3 to 4 seconds between pulses. The homogenate was kept on ice to allow cooling and centrifuged at the same conditions as for muscle-stage larvae and adult worm crude extracts. The protein concentrations were determined by the method of Lowry et al. (1951) and adjusted to $3.5 \mathrm{mg} \mathrm{ml}^{-1}$ for the adult worm crude extracts, to 8 $\mathrm{mg} \mathrm{ml}^{-1}$ for the muscle-stage larvae crude extracts or to 0.5 $\mathrm{mg} \mathrm{ml}^{-1}$ for the newborn extracts. All these homogenates were used immediately or stored at $-80^{\circ} \mathrm{C}$. 
Excretion-secretion products (ESP). Packed viable muscle-stage larvae at a volume of $0.1 \mathrm{ml}$ or approximately 5000 adult worms (3 or 6 days old), were maintained in vitro during $24 \mathrm{~h}$ at $37^{\circ} \mathrm{C}$ in $15 \mathrm{ml}$ of Hank's solution (Sigma) supplemented with 1\% 199 medium and antibiotics (penicillin and streptomycin sulphate). After incubation, the medium were harvested, pooled and dialysed for $24 \mathrm{~h}$ against saline solution $(0.9 \% \mathrm{NaCl})$. The media were concentrated using a Centricon-10 protein concentrator (AMICON, Beverly, MA) with a size exclusion of $10 \mathrm{kDa}$. The protein contents of the resulting concentrates were determined by the method of Lowry et al. (1951) and adjusted to $6 \mathrm{mg} \mathrm{ml}^{-1}$ or $3 \mathrm{mg} \mathrm{ml}^{-1}$ for the ESP of the muscle-stage larvae and adults 3 or 6 days old, respectively.

\section{Assays of proteinase activity}

Substrate gel electrophoresis. The proteolytic activities of the crude extracts and ESP were determined by substrate gel electrophoresis using minigels containing $15 \%(\mathrm{w} / \mathrm{v})$ acrylamide, $0.15 \%(\mathrm{w} / \mathrm{v})$ protein substrate (gelatin, fibrinogen from pig plasma, hemoglobin from pig and anti-human wholemolecule of immunoglobulin $\mathrm{G}$ developed in goat). The samples $(30 \mu \mathrm{g}$ or $26 \mu \mathrm{g}$ per lane) were diluted 3:1 in glycerol $(30 \%)$ and separated electrophoretically at $80 \mathrm{~V}$, using Trisglycine-SDS ( $\mathrm{pH}$ 8.8) buffer or without SDS as running buffers. After electrophoresis, gels were washed in $2.5 \%$ Triton $\mathrm{X}-100$ for $1 \mathrm{~h}$ at $37^{\circ} \mathrm{C}$ to remove the SDS and incubated in $0.1 \mathrm{M}$ Tris-HCl buffer $(\mathrm{pH} 7$ and 8) or $0.1 \mathrm{M}$ citrate buffer ( $\mathrm{pH} \mathrm{3,4}$ and 5) with $2 \mathrm{mM} \mathrm{CaCl}_{2}$ during $24 \mathrm{~h}$ at $37^{\circ} \mathrm{C}$. Finally, the gels were stained for $2 \mathrm{~h}$ with Coomassie Brillant Blue R-250. After destaining, proteases were located as clear bands in a blue gel. These studies were carried out six times with each parasite sample. Results were considered as "+" when at least four of the assays showed degradation bands.

Colorimetric determinations. The colorimetric determinations were carried out by incubation of the samples (crude extracts or ESP) with $5 \mathrm{mg} \mathrm{ml}^{-1}$ of different substrates (azocoll, fibrinogen - fraction 1 from pig plasma, immunoglobulin G - whole molecule goat anti-human G, collagen insoluble collagen from bovine Achilles tendon type $\mathrm{V}$, and hemoglobin - from pig) at $37^{\circ} \mathrm{C}$ over the $\mathrm{pH}$ range $3-8$. After $24 \mathrm{~h}$ of incubation the unhydrolysed substrates were removed by centrifugation (azocoll), acid-precipitation using 6\% trichloroacetic acid (hemoglobin, fibrinogen and immunoglobulin G) or ninhydrin assay (collagen) as described by Armas-Serra et al. (1995). The absorbance of the supernatants was read at 540 (azocoll) or $280 \mathrm{~nm}$ (hemoglobin, fibrinogen and immunoglobulin G), respectively. All the determinations were carried out six times. Results were considered "+" when the mean of all the determinations was statistically different (" $t$ " Student $p<0.05$ ) of the mean of the respective controls.

\section{RESULTS AND DISCUSSION}

The importance of this report is that it constitutes the first study of proteolytic activity throughout the life cycle of the same Trichinella spiralis isolate using general and specific natural substrates, and for this reason it permits clarification of some host/parasite interactions and biological aspects. We have determined the proteolytic activity of the muscle-stage larvae $\left(\mathrm{L}_{1}\right.$, 40 days old), adult worms before and after mating ( 3 or 6 days old, the latter containing the newborn larvae) and newborn larvae (24 h old). The proteolytic activity of $\mathrm{L}_{2}, \mathrm{~L}_{3}$ and $\mathrm{L}_{4}$ was not analysed because it is impossible to obtain all the worms in the same developmental time (Despommier 1983, Soulé 1991). The results obtained in this study are reflected in Table 1, showing the presence or absence of the proteolytic activity in the different samples assayed with several substrates, as well as the optimal $\mathrm{pH}$ conditions for these activities. All the samples analysed degraded general substrates (azocoll and gelatin), corroborating the presence of proteolytic enzymes in all the $T$. spiralis developmental stages (Criado-Fornelio et al. 1992, Armas-Serra et al. 1995, Todorova et al. 1995, Moczon and Wranicz 1999). We also detected activity against these substrates by the ESP, indicating that some of these enzymes are secreted, like in other parasitic helminths (Knox 1994). It is also interesting to note, that each sample degraded gelatin and/or azocoll at different optimal $\mathrm{pH}$ (Table 1, Fig. 1), reflecting a possible stage-specificity of these enzymes as previously reported for other parasites, protozoan and metazoan (Wertheim et al. 1983, Newport et al. 1987, Knox and Kennedy 1988, McKerrow and Dohenhoff 1988, Britton et al. 1992). Moreover, the concordance determined between optimal $\mathrm{pH}$ of the different developmental stages and the $\mathrm{pH}$ that the parasite finds in its localisations, corroborate the biological importance of the proteases. ESP musclestage larvae and newborn crude extract (developmental stages with enteral and parenteral locations) show proteolysis at acid and neutral $\mathrm{pH}$ values, while ESP of the intestinal adults only degrade gelatin at acid $\mathrm{pH}$.
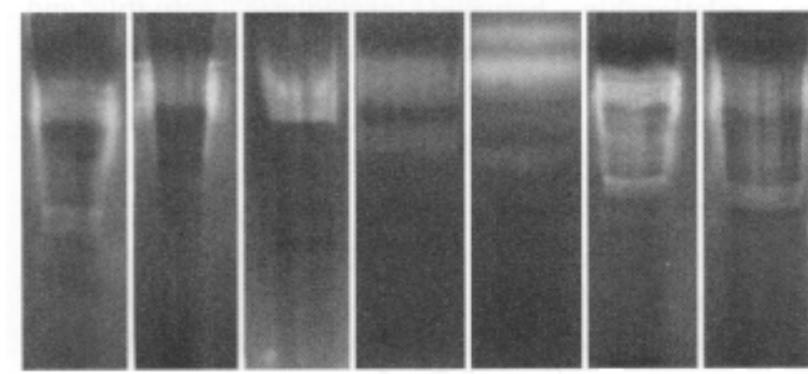

A

B

C

D

E

$\mathrm{F}$

Fig. 1. Gelatin degradation by excretion-secretion products (ESP) and crude extracts of Trichinella spiralis adult worms (3 and 6 days old), muscle-stage larvae and newborn, using gelatin gel electrophoresis method and incubation at the optimal pH. Crude extracts: (A) 3-day-old adult worms, $\mathrm{pH} 7$; (B) 6-day-old adult worms, $\mathrm{pH} 7$; (C) muscle-stage larvae, $\mathrm{pH}$ 4; (D) newborn larvae, $\mathrm{pH}$ 7. ESP: (E) 3-day-old adults, $\mathrm{pH} 4$; (F) 6-day-old adults, $\mathrm{pH} 4$; (G) muscle-stage larvae, $\mathrm{pH} 4$. 
Table 1. Proteolytic activity determined in the excretion-secretion products (ESP) and crude extracts of Trichinella spiralis, 3- and 6-day-old adult worms (before and after mating), muscle-stage larvae and newborn, against natural substrates. The results indicate the presence $(+)$ or absence $(-)$ of activity at acid, neutral and basic $\mathrm{pH}$.

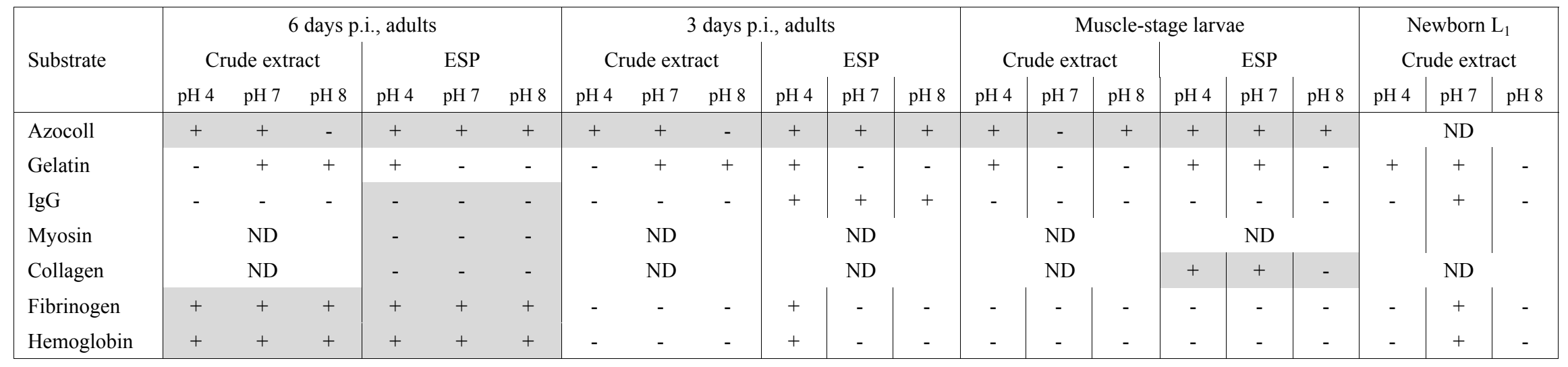

Shaded areas: spectrophotometrically determined Non-shaded areas: electrophoretically determined ND: not determined 
The possible implications of these activities in vital processes such as establishment, feeding, migration of the parasite or evasion of host immune response, as previously proposed by McKerrow et al. (1990), Todorova et al. (1995) and Vázquez-López et al. (1999), were analysed by proteolysis of specific natural substrates, mammalian structural proteins (myosine and collagen) and mammalian hematic proteins (hemoglobin, fibrinogen and immunoglobulin G). These results show again a stage-specificity of the proteolytic activities. We only have determined collagenolytic activity by muscle-stage larvae (ESP), but not by the adult worms analysed. Fibrinolytic and hemoglobinolytic activities were detected by adults 6 days old and newborn crude extracts and by ESP of 3- and 6-day-old adults, but at different $\mathrm{pH}$. It is possible that these different activities shown between crude extracts of 3and 6-day-old adults were due to the presence or absence of newborn larvae with their proteases, in the uterus, because it is known that at 5 days p.i. every Trichinella female contains fertilised eggs (Despommier 1983, Soulé 1991). Finally, digestion of immunoglobulin G was only detected by ESP of 3-day-old adults and newborn crude extracts.

With respect to the importance of these activities in the parasite biology and host/parasite interrelationships, it is interesting to remember and to analyse the $T$. spiralis life cycle along with our results on specific proteolytic activities and its optimal $\mathrm{pH}$ conditions. The muscle-stage larva $\left(\mathrm{L}_{1}\right)$ is the infective larva that penetrates into the enterocytes to undergo the moulting processes $\left(\mathrm{L}_{2}, \mathrm{~L}_{3}, \mathrm{~L}_{4}\right.$ and adults) (Despommier 1983, Soule 1991). The cleavage of collagen (one of the major intestinal structural proteins) at acid $\mathrm{pH}$ by ESP muscle larvae could indicate that the parasite secretes proteases at this time to facilitate its intestinal establishment, as occurs in other intestinal nematodes (Kennedy et al. 1988). After 72 h p.i. (3 days p.i.) females and males copulate and at 5 days p.i. begins the newborn production and then these migrate via the lymphatic vessel and/or the capillary to their muscular location. There they induce nurse cell formation, increasing the amount of collagen (Despommier 1983). In this position, the muscle-stage larvae collagenolytic activity will again be essential to the exchange of the ESP and nutrients between host and the parasite.

It is possible that all the newborn migration processes are also facilitated by proteases, as proposed by Moczon and Wranicz (1999). The fibrinolytic activity shown by the adults ( 3 and 6 days old) and newborn larvae could indicate an anticoagulant role to facilitate the newborn migration by the sanguineous system. This activity has previously been described in other helminths and associated with these processes, as well as nutritional mechanisms in hematophagous parasites (Hotez et al. 1985, Todorova et al. 1995). Moreover, this migration may also be facilitated by the immunoglobulin $G$ degradation shown by ESP of 3-day-old adults as well as newborn, which constitutes a very common evasion of host immune response mechanism reported in other parasites (Matsumoto et al. 1984, Carmona et al. 1993). Note also the inability of the 6day-old adults to degrade immunoglobulin $G$, data previously described by Todorova et al. (1995). This situation could be explained by the fact that at this time the parasite evades the intestinal humoral immune response by the proteases against immunoglobulin $G$ released by adults before 6 days p.i. which are stored in the intestinal tissues, as well as by the ability of newborn larvae to degrade immunoglobulin G. The mission of the 6-day-old adults may be to facilitate the newborn migration by the production of proteases against fibrinogen.

Finally, with respect to the activity against hemoglobin, although little information is available on nutrition of Trichinella, and no evidence for ingestion of host blood (Despommier 1983), it is possible that these proteases are used by Trichinella in its nutrition, as occurs with other parasites (Davis et al. 1987, Pritchard et al. 1990). Moreover, note that only adult worms ( 3 and 6 days old) and newborn larvae, developmental stages in close relationship with the hematic system, posses this activity (Despommier 1983, Soulé 1991). This fact could be corroborated by the correlation between optimal $\mathrm{pH}$ of these activities and the $\mathrm{pH}$ present in the location of the different developmental stages. Three-day-old intestinal adults degrade hemoglobin at acid $\mathrm{pH}$ only, while sanguineous newborn larvae digest this substrate specifically at neutral $\mathrm{pH}$. In this respect, note again a different behaviour of adults before and after mating. It is possible that this fact is due, in part, to the presence or absence of the newborn in the uterus; although, the 6-day-old adults have also some stage-specific proteolytic activity, not due to the presence of newborn larvae. So, ESP of 3day-old adults shows these activities against fibrinogen and hemoglobin at $\mathrm{pH} \mathrm{4,} \mathrm{newborn} \mathrm{larvae} \mathrm{crude} \mathrm{extract}$ at $\mathrm{pH} 7$ and ESP of 6-day-old adults at $\mathrm{pH} \mathrm{4,7}$ and 8 .

All these results lead us to draw the following conclusions that may be helpful to clarify some biological aspects of the $T$. spiralis life cycle, as well as host/parasite interrelationships. The conclusions are: i) the different developmental stages of $T$. spiralis possess proteases; ii) some of these enzymes are released; iii) the proteolytic pattern showed certain stage-specificity; iv) the muscle-stage larvae proteolytic activity against collagen could be involved in parasite establishment into enterocytes as well as in the exchange of the parasite ESP and host nutrients when the larvae are in the muscular capsule; v) the hemoglobinolytic, fibrinolytic and the activity against immunoglobulin $G$ shown by the adult worms may be involved in nutrition and 


\section{HOST}

\section{ENTERAL LOCATION:}
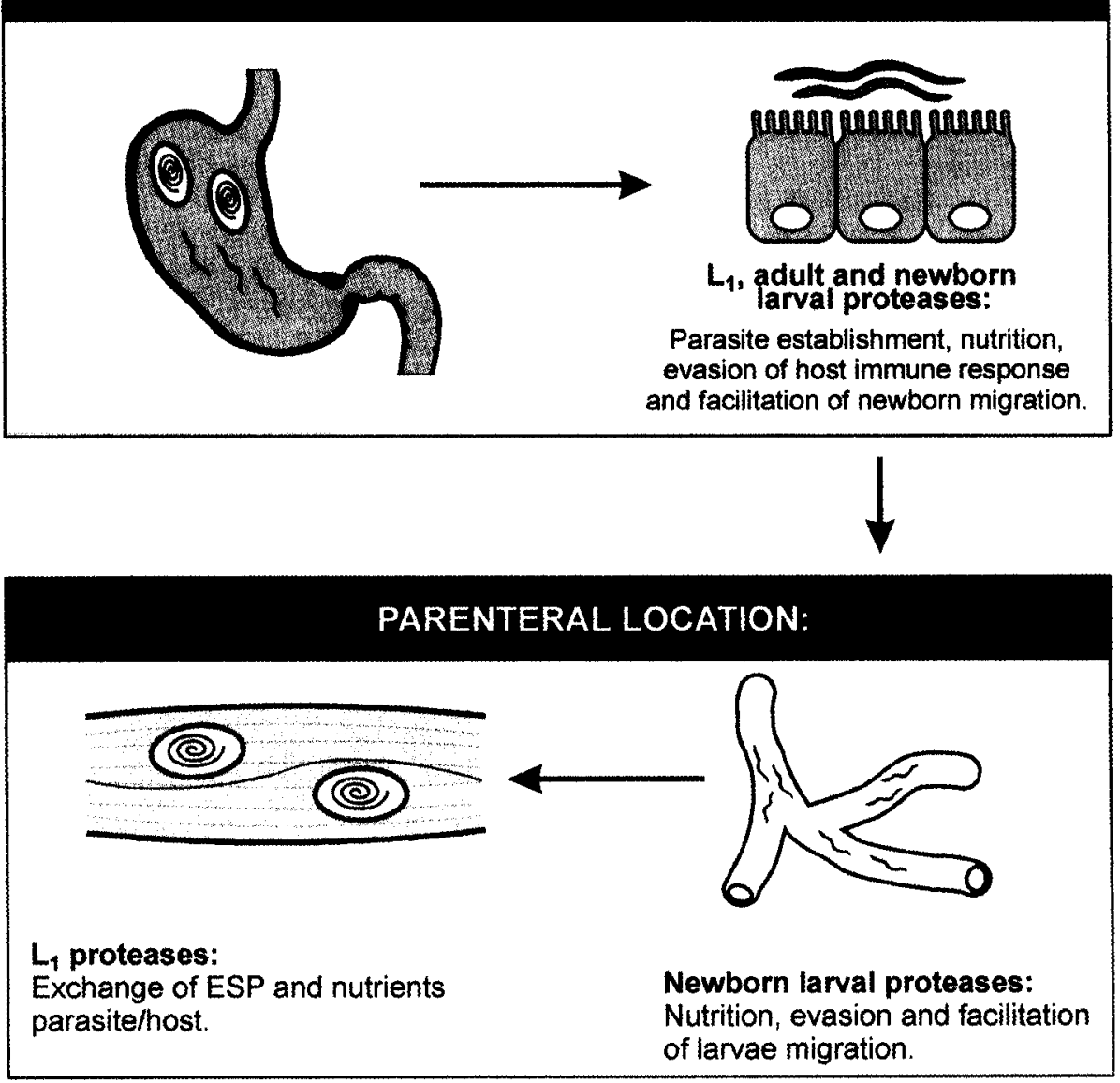

Fig. 2. Implication of the proteolytic activity in the life cycle of Trichinella spiralis.

penetration into the enterocytes, as well as facilitate the newborn migration by anticoagulant and evasion of host immune response mechanisms; vi) the capacity of the newborn larva to degrade immunoglobulin $G$ and fibrinogen could facilitate its migration until the final location, and its hemoglobinolytic activity could be implicated in nutritional processes. We summarise all these results and conclusions in Fig. 2.

Acknowledgement. We would like to thank M.J. Moreno for her editorial assistance.

\section{REFERENCES}

ARMAS-SERRA C. de, GIMENEZ-PARDO C., JIMENEZGONZALEZ A., BERNADINA W.E, RODRIGUEZCAABEIRO F. 1995: Purification and preliminary characterization of a protease from the excretion-secretion products of Trichinella spiralis muscle-stage larvae. Vet. Parasitol. 59: 157-168.

BRAND T., WEISTEIN P., MEHLAN B., WEINBACH E. 1952: Observation on the metabolism of bacteria larvae Trichinella spiralis. Exp. Parasitol. 1: 245-255.
BRITTON C., KNOX D.P., CANTO G.J., URQUHART G.M., KENNEDY M.W. 1992: The secreted and somatic proteinases of the bovine lungworm Dictyocaulus viviparus and their inhibition by antibody from infected and vaccinated animals. Parasitology 105: 325-333.

CARMONA C., DOWD A., SMITH A., DALTON J.P. 1993: Fasciola hepatica: cathepsin L proteinase secreted in vitro prevents antibody-mediated eosinophil attachment to newly excysted juveniles. Mol. Biochem. Parasitol. 62: 918. 
CRIADO-FORNELIO A., ARMAS-SERRA C. de, GIMÉNEZ-PARDO C., CASADO-ESCRIBANO N., JIMÉNEZ-GÓNZALEZ A., RODRÍGUEZ-CAABEIRO F. 1992: Proteolytic enzymes from Trichinella spiralis larvae. Vet. Parasitol. 45: 133-140.

DAVIS A.H., NANDUIN J., WATSON D.C. 1987: Cloning and gene expression of Schistosoma mansoni protease. J. Biol. Chem. 262: 12581-12585.

DESPOMMIER D.D. 1983: Biology. In: W. C. Campbell (Ed.), Trichinella and Trichinosis. Plenum Press, New York and London, pp. 75-151.

HOTEZ P.J., NGUYEN L.T., McKERROW J.H., CERAMI A. 1985: Isolation and characterization of a proteolytic enzyme from the adult hookworm Ancylostoma caninum. J. Biol. Chem. 260: 7343-7348.

KENNEDY M.W., TIERNEY J., YE P., McMONGALE F.A., MACINTOSH A., McLAUGHLIN D., SMITH J.W. 1988: The secreted and somatic antigens of the third stage larva of Anisakis simplex and the antigenic relationship with Ascaris suum, A. lumbricoides and Toxocara canis. Mol. Biochem. Parasitol. 31: 35-46.

KNOX D.P. 1994: Parasite enzymes and the control of roundworm and fluke infestation in domestic animals. Br. Vet. J. 150: 319-338.

KNOX D.P., KENNEDY M.W. 1988: Proteinases released by the parasitic larval stages of Ascaris suum and their inhibition by antibody. Mol. Biochem. Parasitol. 28: 207216.

LOWRY O.H., ROSEBROUGH N.J., FARR A.L., RANDALL R.J. 1951: Protein measurement with the folin phenol reagent. J. Biol. Chem. 193: 265-275.

MATSUMOTO K., YAKAMOTO T., KAMATA R., MAEDA H. 1984: Pathogenesis of serratial infection: activation of Hageman factor-prekallicrein cascades and serratia protease. J. Biochem. 96: 739.

McKERROW J.H., BRINDLEY P., BROWN M., GAM A.A., STAUTON C., NEVAF A. 1990: Strongyloides stercoralis: identification of a protease that facilitates penetration of skin by the infective larvae. Exp. Parasitol. 70: 134-143.

McKERROW J.H., DOHENHOFF M.J. 1988: Schistosoma proteases. Parasitol. Today 4: 334-340.

MOCZON T., WRANICZ M. 1999: Trichinella spiralis: proteinases in the larvae. Parasitol. Res. 85: 47-58.

NEWPORT G., McKERROW J.H., BARR P., AGABAIN N. 1987: Stage specific expression of schistosome proteases. In: N. Agabain, H. Goodman and N. Nogueira (Eds.), Modular Strategies of Parasitic Invasion. Alan R. Liss, Inc., New York, pp. 121-131.

POLZER M., CONRADT V. 1994: Identification and partial characterization of the proteases from different developmental stages of Schistocephalus solidus (Cestoda: Pseudophyllidea). Int. J. Parasitol. 24: 967-973.

PRITCHARD D.I., McKEAN P.G., SCHAD G.A. 1990: An immunological and biochemical comparison of hookworm species. Parasitol. Today 6: 154-156.

SOULÉ C. 1991: Etude du parasite. In: C. Soulé and J. Dupoy-Camet (Eds.), La Trichinellose: une Zoonose en Évolution. Office International des Epizooties, Paris, France, pp. 7-42.

TODOROVA V.K., KNOX D.P., KENNEDY M.W. 1995: Proteinases in the excretory/secretory products (ES) of adult Trichinella spiralis. Parasitology 111: 201-208.

VÁZQUEZ-LÓPEZ C., ARMAS-SERRA C. de, GIMÉNEZPARDO C., RODRÍGUEZ-CAABEIRO F. 1999: Proteolytic activity of the Gymnorhynchus gigas plerocercoid: purification and properties of a collagenase from the crude extract. Parasitol. Res. 85: 64-70.

WERTHEIM G., LUSTIGMAN S., SILBERMAN H., SHOSHAN S. 1983: Demonstration of collagenase activity in adult Strongyloides ratti (Nematoda: Strongyloididae) and its absence in the infective larvae. J. Helminthol. 57: 241-246.

Accepted 15 September 1999 